\title{
Treatment of Anemia with Darbepoetin Alfa Administered de novo Once Every Other Week in Chronic Kidney Disease
}

\author{
Michael G. Suranyi ${ }^{a}$ J ill S. Lindberg ${ }^{b}$ J esus Navarro ${ }^{c}$ Chester Elias $^{d}$ \\ Robert M. Brennerd Rowan Walkere \\ aLiverpool Hospital, Sydney, Australia; bAlton Ochsner Medical Foundation, New Orleans, La., \\ 'Genesis Clinical Research Corporation, Tampa, Fla., and dAmgen Inc., Thousand Oaks, Calif., USA; \\ eRoyal Melbourne Hospital, Melbourne, Australia
}

\section{Key Words}

Darbepoetin alfa · Aranesp · Anemia · Chronic kidney disease

\begin{abstract}
Background/Aims: Darbepoetin alfa is an erythropoiesis-stimulating protein that works via the same mechanism and has a threefold longer serum half-life than recombinant human erythropoietin (rHuEPO). The objective of this study was to evaluate extending the dosing interval of darbepoetin alfa to once every other week administration for the treatment of anemia in patients with chronic kidney disease (CKD) not requiring dialysis who were naive to rHuEPO therapy. Methods: This was a multi-center, open-label study. Seventy-six rHuEPOnaive patients were enrolled to receive darbepoetin alfa $(0.75 \mu \mathrm{g} / \mathrm{kg})$ once every other week for up to 24 weeks. Doses were titrated to achieve and maintain a hemoglobin target of 11.0 to $13.0 \mathrm{~g} / \mathrm{dl}$. Results: Ninety-seven percent $(95 \% \mathrm{Cl}: 0.92,1.00)$ of patients completing 24 weeks of treatment achieved a hemoglobin response. The median time to response was 5 weeks (range 1-25 weeks). The median darbepoetin alfa dose at the time of re-
\end{abstract}

sponse was $60 \mu \mathrm{g}$ (range 30-130 $\mu \mathrm{g}$ ). Darbepoetin alfa was safe and well tolerated, and no antibodies to darbepoetin alfa were detected. Conclusion: These results demonstrate the utility of darbepoetin alfa administered once every other week in rHuEPO-naive CKD patients. This new treatment paradigm may allow for more widespread management of anemia in patients with CKD.

Copyright $\odot 2003$ S. Karger AG, Basel

\section{Introduction}

Anemia frequently develops at an early stage in chronic kidney disease (CKD) and is an important determinant of patient well-being and clinical outcomes. Although increased attention is being paid to the use of erythropoietic therapy in patients with CKD [1], anemia in these patients remains prevalent and undertreated [2]. A recent report on US trends in anemia at initiation of dialysis indicates only a slight improvement from 1995 to 1999 in the management of anemia in these patients, despite the introduction of recombinant human erythropoietin (rHuEPO) more than a decade ago [3]. Many patients, including three fourths of those who initiate

\section{KARGER}

Fax + 41613061234 E-Mail karger@karger.ch www. karger.com
(C) 2003 S. Karger AG, Base

0250-8095/03/0232-0106\$19.50/0

Accessible online at:

www. karger.com/ajn
Michael G. Suranyi, MD

Liverpool Hospital

Elizabeth Street

Liverpool, Sydney 2170 (Australia)

Tel. +61 29828 3708, Fax +61 29828 3718, E-Mail Michael.Suranyi@swsahs.nsw.gov.au 
chronic dialysis, still have hemoglobin levels significantly lower than the 11.0- to $12.0 \mathrm{-g} / \mathrm{dl}$ guideline recommended by the National Kidney Foundation - Kidney Disease Outcomes Quality Initiative [3, 4]. One significant obstacle to routine anemia management in CKD patients has been the need for frequent injections of rHuEPO.

Darbepoetin alfa is a unique erythropoiesis-stimulating glycoprotein that binds to and activates the same receptor as rHuEPO and endogenous erythropoietin [5]. Darbepoetin alfa was designed by modifying the primary amino acid sequence of rHuEPO, introducing two additional sialic acid-containing carbohydrate chains [6]. The increased sialic acid content of darbepoetin alfa results in a threefold longer terminal half-life than rHuEPO (25.3 vs. $8.5 \mathrm{~h}$ ) [7], providing greater biological activity and increased red blood cell production over time.

Darbepoetin alfa, administered once weekly, has been shown to be a safe and effective treatment for anemia in rHuEPO-naive CKD patients not requiring dialysis [8]. The current study was undertaken to investigate the utility of extending the dosing interval of darbepoetin alfa to once every other week in this patient population. Extending the dosing interval of darbepoetin alfa would be expected to provide significant benefits to both patients and health care providers by decreasing the number of clinic visits and decreasing the number of injections required.

\section{Patients and Methods}

\section{Patients}

All patients provided written informed consent prior to beginning any study-related procedures. To be eligible for the study, patients were required to be at least 18 years of age, have a mean baseline hemoglobin concentration $<11.0 \mathrm{~g} / \mathrm{dl}$, and to have creatinine clearance $<40 \mathrm{ml} / \mathrm{min}$ as estimated by the Cockroft-Gault equation. These patients were also required to have serum $\mathrm{B}_{12}$ and folate concentrations above the lower limit of the normal range and to have either a serum ferritin $\geq 100 \mu \mathrm{g} / \mathrm{l}$ or transferrin saturation $\geq 20 \%$. In addition, patients were not to have received rHuEPO therapy within 12 weeks of study entry, blood transfusions within 8 weeks of enrollment, and were not expected to initiate dialysis within 24 weeks after study entry.

\section{Study Design}

This was a multicenter, open-label study, conducted in Australia and the United States. Upon completion of a 2-week screening period, all eligible patients were enrolled into a 24-week treatment period followed by a 1-week post-treatment and evaluation period. Eligible, anemic CKD patients were treated with fixed doses of darbepoetin alfa $(10,15,20,30,40,50,60,80$ and $100 \mu \mathrm{g})$, administered by subcutaneous injection every other week for up to 24 weeks. The starting dose of darbepoetin alfa was $0.75 \mu \mathrm{g} / \mathrm{kg}$, rounded to the nearest fixed- dose strength. Patients were evaluated according to their ability to achieve a hemoglobin response and to maintain a hemoglobin concentration within the target range of 11.0-13.0 g/dl. Hemoglobin measurements were obtained every 2 weeks during the study.

The dose of darbepoetin alfa was titrated as necessary to maintain a hemoglobin rate of rise between 1.0 and $3.0 \mathrm{~g} / \mathrm{dl}$ during 4-week intervals until the target range was achieved. Any hemoglobin value outside of the target range was confirmed with a repeat measurement. The dose of darbepoetin alfa was adjusted to the next higher or lower dose strength when two consecutive hemoglobin values were outside the target range.

\section{Efficacy Endpoints}

Patients were judged to have achieved a hemoglobin response when they reached the hemoglobin target range (11.0-13.0 g/dl). The primary efficacy endpoint was the proportion of patients who achieved a hemoglobin response. Secondary endpoints included the time to hemoglobin response, darbepoetin alfa dose at the time of response, and change in mean hemoglobin over time.

\section{Safety Endpoints}

The safety and tolerability of darbepoetin alfa were assessed by the monitoring of adverse events, laboratory tests, and testing for antibodies to darbepoetin alfa. Serum chemistry and iron status were evaluated pretreatment, at weeks 11 and 23 , and at the end of the study.

\section{Statistical Analyses}

For continuous variables, descriptive statistics were computed such as mean, median, range, and standard deviation. Percentages and sample sizes were used to summarize categorical variables.

For the primary efficacy endpoint, a point estimate and $95 \%$ confidence interval were computed using the number of patients who reached the hemoglobin target range of $11.0-13.0 \mathrm{~g} / \mathrm{dl}$ divided by the number of patients who completed 24 weeks of treatment with darbepoetin alfa.

For the safety analyses, counts and percentages were calculated for adverse events. Adverse event rates were examined for the demographic subsets age ( $<65, \geq 65$ or $\geq 75$ years), race (white, black or other), and sex.

Descriptive statistics for continuous variables were calculated using SAS version 8.0.

\section{Results}

\section{Study Population}

Patient demographics and baseline characteristics are summarized in table 1 . The majority of patients enrolled into the study were female $(61 \%)$ and white $(54 \%)$; the median age at study entry was 65 years. At baseline the patients' mean hemoglobin concentration was $9.9 \pm$ $0.1 \mathrm{~g} / \mathrm{dl}$, and their mean creatinine clearance was $21.4 \pm$ $1.1 \mathrm{ml} / \mathrm{min}$. The two most common etiologies of CKD in these patients were hypertension (19 patients, 31\%) and diabetes (17 patients, 28\%). 
Table 1. Patient demographics and baseline characteristics

\begin{tabular}{lc}
\hline Patients enrolled & 76 \\
Patients who received study drug & 75 \\
Patients completing darbepoetin alfa treatment & 61 \\
Age, years (range) ${ }^{\mathrm{a}}$ & $62 \pm 2.1$ \\
Sex, $\mathrm{n}(\%)$ & \\
$\quad$ Male & $24(39.3)$ \\
$\quad$ Female & $37(60.7)$ \\
Race, $\mathrm{n}(\%)$ & \\
$\quad$ White & $33(54.1)$ \\
$\quad$ Black & $19(31.1)$ \\
$\quad$ Asian & $5(8.2)$ \\
$\quad$ Other & $4(6.6)$ \\
Body weight, kg & $73.8 \pm 2.2$ \\
Hemoglobin concentration, g/dl ${ }^{\mathrm{a}}$ & $9.9 \pm 0.1$ \\
Transferrin saturation, \% ${ }^{\mathrm{a}}$ & $31.4 \pm 2.2$ \\
Serum ferritin concentration, $\mu \mathrm{g} / \mathrm{l}^{\mathrm{a}}$ & $340.0 \pm 33.8$ \\
Creatinine clearance, ml/min ${ }^{\mathrm{a}}$ & $21.4 \pm 1.1$ \\
Primary cause of renal insufficiency, $\mathrm{n}(\%)$ & \\
$\quad$ Diabetes & $17(27.9)$ \\
Hypertension & $19(31.1)$ \\
Glomerulonephritis & $8(13.1)$ \\
Polycystic kidney disease & $1(1.6)$ \\
Other & $15(24.6)$ \\
Unknown & $1(1.6)$ \\
&
\end{tabular}

Summary statistics are based on the number of patients who completed 24 weeks of darbepoetin alfa treatment.

a Data are shown as mean $\pm \mathrm{SE}$.

Table 2. Patient disposition

\begin{tabular}{lc}
\hline Patients enrolled & 76 \\
Patients who received study drug & 75 \\
Patients completing 24 weeks of darbepoetin alfa & \\
$\quad$ treatment & 61 \\
Patients discontinued from treatment & 15 \\
$\quad$ Initiation of chronic dialysis therapy & $7(47 \%)$ \\
Death & $2(13 \%)$ \\
Inclusion criteria violation & $1(7 \%)$ \\
Investigator decision & $2(13 \%)$ \\
Lost to follow-up & $2(13 \%)$ \\
Adverse event & $1(7 \%)$ \\
\hline
\end{tabular}

a Determined by principal investigator to be unrelated to darbepoetin alfa administration. Cause of death was myocardial infarction and pulmonary edema, respectively.
Table 3. Hemoglobin response

\begin{tabular}{lc}
\hline $\begin{array}{l}\text { Patients completing treatment } \\
\text { Achievement of hemoglobin response }\end{array}$ & 61 \\
$\quad$ (target range, $11.0-13.0 \mathrm{~g} / \mathrm{dl}$ & \\
$\quad \begin{array}{l}\text { Number of patients } \\
\text { Proportion of patients }\end{array}$ & 0.97 \\
95\% confidence interval for proportion & $(0.92,1.00)$ \\
$\quad$ Median time to response, weeks range & $5(1-25)$ \\
Median darbepoetin alfa dose at time of hemoglobin & \\
$\quad$ response, $\mu$ g every other week & 60.0 \\
Range & $30.0-130.0$
\end{tabular}

All analyses are based on the 61 patients who completed treatment (table 2). A total of 76 patients were enrolled into the study (25 in Australia and 51 in the United States). One patient did not receive study drug. Sixty-one patients completed 24 weeks of treatment with darbepoetin alfa. Seven of the 15 patients who did not complete treatment discontinued study participation because of renal disease progression requiring the initiation of dialysis. Further analysis of these 7 patients revealed a median baseline creatinine clearance of $16.6 \mathrm{ml} / \mathrm{min}$ (range $10-20 \mathrm{ml} / \mathrm{min}$ ), indicating stage $4-5$ kidney disease [9].

\section{Efficacy}

As shown in table 3, 97\% (95\% CI: $0.92,1.00)$ of patients who completed treatment achieved a hemoglobin response (target range 11.0-13.0 g/dl). The median time to hemoglobin response was 5 weeks (range 1-25 weeks), and the median darbepoetin alfa dose at the time of response was $60 \mu \mathrm{g}$ (range 30-130 $\mu \mathrm{g}$ ). As shown in figure 1 , the mean hemoglobin concentration reached the target range at week 5 and was sustained within the target range through the end of the study.

Safety

Darbepoetin alfa was safe and well tolerated in this study. Adverse events were consistent with those expected in the CKD population and with the known safety profile of darbepoetin alfa. Table 4 includes adverse events that occurred in at least $5 \%$ of the patients who received study drug. Sixty-four patients reported at least one adverse event during the course of the study. The most frequently reported adverse event was hypertension (occurring in $19 \%$ of the patients). Of the adverse events reported in table 4, only two events were reported as being treatmentrelated by the investigator. These events were hyperten- 


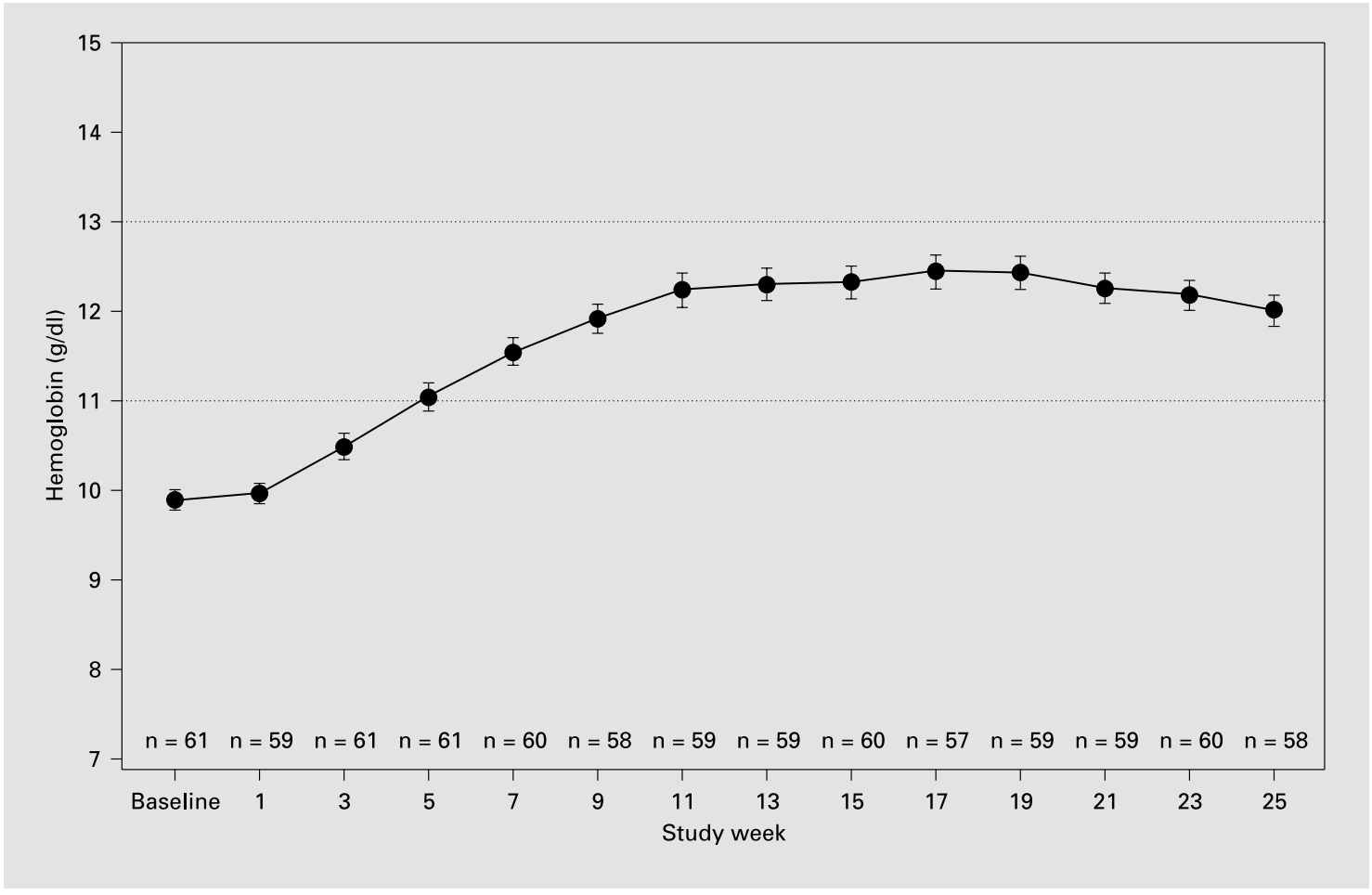

Fig. 1. Mean $( \pm S E)$ hemoglobin concentration by study week.

sion and injection site stinging. All adverse events were analyzed according to age, sex, and race and no notable trends were apparent. Two deaths were reported during the course of the study. One patient with a history of coronary artery disease, peripheral vascular disease, and cerebrovascular accident died as a result of a myocardial infarction. A second patient with a history of congestive heart failure, chronic obstructive pulmonary disease, hypertension, and diabetes mellitus died of pulmonary edema. All patients were screened for the production of antibodies to darbepoetin alfa and none were detected.

\section{Discussion}

The benefit of treating anemia in patients with CKD not requiring dialysis has been described by others and is well established. Replacement therapy with rHuEPO, which has been available for more than a decade, eliminates the need for red blood cell transfusions, reduces symptoms associated with anemia, and improves energy and physical functioning $[8,10-12]$.
Table 4. Patient incidence of adverse events occurring in $\geq 5 \%$ of patients

\begin{tabular}{lrr} 
Adverse event & \multicolumn{2}{c}{$\begin{array}{c}\text { Patients } \\
(\mathrm{n}=75)\end{array}$} \\
\cline { 2 - 3 } & $\mathrm{n}$ & $\%$ \\
\hline Number of patients reporting at least one adverse event & 64 & 85 \\
Hypertension & 14 & 19 \\
Renal failure & 9 & 12 \\
Peripheral edema & 7 & 9 \\
Diarrhea & 6 & 8 \\
Upper respiratory tract infection & 6 & 8 \\
Urinary tract infection & 5 & 7 \\
Fatigue & 4 & 5 \\
Fall & 4 & 5 \\
Constipation & 4 & 5 \\
Gastrointestinal hemorrhage & 4 & 5 \\
Ecchymosis & 4 & 5 \\
Dehydration & 4 & 5
\end{tabular}


Despite the introduction of $\mathrm{rHuEPO}$ more than 10 years ago, recent studies suggest that the management of anemia prior to the initiation of dialysis in CKD patients is suboptimal $[3,13]$. Although some improvement has occurred in recent years, it is clear that anemia continues to be under-recognized and under-treated in this patient population. An analysis of data from June 1995 to June 1999 provided by the U.S. Health Care Financing Administration (as of 2001, the Centers for Medicare and Medicaid Services) indicates that despite a modest increase from 21.8 to $28.1 \%$ in the annual percentage of CKD patients receiving $\mathrm{rHuEPO}$, the increase in mean hematocrit at initiation of dialysis was minimal, from 28.1 to $29.3 \%$, and well below the target range of $33-36 \%$ recommended by the NKF-K/DOQI guidelines [3, 4]. Furthermore, three fourths of patients who start chronic dialysis have predialysis hematocrit levels below the NKF-K/ DOQI recommendation [3].

Although the introduction of rHuEPO in 1989 transformed the management of anemia, the requirement for frequent rHuEPO injections, up to three times weekly, has been an obstacle to optimal anemia management in CKD patients. Darbepoetin alfa was designed to have a prolonged duration of action and to allow for an extended dosing interval relative to rHuEPO. Pharmacokinetic studies have confirmed the longer serum half-life of darbepoetin alfa compared with $\mathrm{rHuEPO}[7,14]$. Locatelli et al. [8] demonstrated that once-weekly administration of darbepoetin alfa achieved and maintained a hemoglobin response (target range $11.0-13.0 \mathrm{~g} / \mathrm{dl}$ ) in $92 \%$ of rHuEPOnaive patients with CKD. The goal of the current study was to determine if extending the interval of de novo darbepoetin alfa administration to once every other week would be effective and safe in the management of anemia in CKD.

The results of this study demonstrate that darbepoetin alfa, when administered de novo once every other week corrects and maintains hemoglobin concentrations in CKD patients. Ninety-seven percent of the 61 patients who completed 24 weeks of therapy were able to achieve the hemoglobin target of $11.0-13.0 \mathrm{~g} / \mathrm{dl}$ in a median time of 5 weeks. The median darbepoetin alfa dose at the time of hemoglobin response was $60 \mu \mathrm{g}$ once every other week. Safety monitoring did not reveal any unexpected adverse events in this CKD population, which is consistent with previous studies that demonstrated that the safety profile of darbepoetin alfa and rHuEPO are comparable [15, 16].

In a recent pilot study in dialysis patients, the maintenance dosing interval of darbepoetin alfa was extended from once every other week to once monthly. Hemoglobin concentrations were maintained within a 10.0- to $13.0-\mathrm{g} / \mathrm{dl}$ target range in more than $80 \%$ of these patients [17]. Taken together, these data suggest that an optimized darbepoetin alfa dosing paradigm would include the initiation of darbepoetin alfa therapy once every other week until patients achieve the target hemoglobin range outlined by NKF-K/DOQI guidelines [4]. Upon reaching the target hemoglobin range, patients could then be titrated to a once-monthly dosing interval. Extending the dosing interval of darbepoetin alfa may allow for a greater number of patients to benefit from appropriate CKD anemia management and may also contribute to improved clinical outcomes in this patient population.

\section{Acknowledgments}

We are thankful to Denise Mathes and Frances Passuello for assistance in conducting the study, Nancy Picarello for safety monitoring and analysis, Richard Baumann for statistical programming, John Feaster and Nacer Abrouk for statistical analysis, and Michele Vivirito and Eve Thomas for assistance in writing the manuscript.

\section{References}

1 Nissenson AR: Novel erythropoiesis stimulating protein for managing the anemia of chronic kidney disease. Am J Kidney Dis 2001;38: 1390-1397.

2 Kausz AT, Obrador GT, Pereira BJG: Anemia management in patients with chronic renal insufficiency. Am J Kidney Dis 2000;36(suppl 3):S39-S51.

3 Obrador GT, Roberts T, St. Peter WL, Frazier E, Pereira BJG, Collins AJ: Trends in anemia at initiation of dialysis in the United States. Kidney Int 2001;60:1875-1884.
4 National Kidney Foundation: K/DOQI clinical practice guidelines for anemia of chronic kidney disease, 2000. Am J Kidney Dis 2001; 37(suppl 1):S182-S238.

5 Macdougall IC: Novel erythropoiesis stimulating protein. Semin Nephrol 2000;20:375-381.

6 Egrie J, Browne JK: Development and characterization of novel erythropoiesis stimulating protein (NESP). Nephrol Dial Transplant 2001;16(suppl 3):3-13.
7 Macdougall IC, Gray SJ, Elston O, Breen C, Jenkins B, Browne J, Egrie J: Pharmacokinetics of novel erythropoiesis stimulating protein compared with epoetin alfa in dialysis patients. J Am Soc Nephrol 1999;10:2392-2395.

8 Locatelli F, Olivares J, Walker R, Wilkie M, Jenkins B, Dewey C, Gray SJ, for the European/Australian NESP 980202 Study Group: Novel erythropoiesis stimulating protein for treatment of anemia in chronic renal insufficiency. Kidney Int 2001;60:741-747. 
9 Levey AS, Coresh J, Bolton K, Culleton B, Harvey KS, Ikizler TA, Johnson CA, Kausz A, Kimmel PL, Kusek J, Levin A, Minaker KL, Nelson R, Rennke H, Steffes M, Witten B, Hogg RJ, Furth S, Lemley KV, Portman RJ, Schwartz G, Lau J, Balk E, Perrone RD, Karim T, Rayan L, Al-Massry I, Chew P, Astor BC, De Vine D, Eknoyan G, Levin N, Burrows-Hudson S, Keane W, Kliger A, Latos D, Mapes D, Oberley E, Willis K, Bailie G, Becker G, Burrowes J, Churchill D, Collins A, Couser W, DeZeeuw D, Garber A, Golper T, Gotch F, Gotto A, Greer JW, Grimm R, Hannah RG, Acosta JH, Hogg R, Hunsicker L, Klag M, Klahr S, Lewis C, Lowrie E, Matas A, McCulloch S, Michael M, Nally JV, Newmann JM, Nissenson A, Norris K, Owen W, Patel TG, Payne G, Rivera-Mizzoni RA, Smith D, Star R, Steinman T, Valderrabano F, Walls J, Wauters J-P, Wenger N, Briggs J: K/DOQI clinical practice guidelines for chronic kidney disease: Evaluation, classification, and stratification. Am J Kidney Dis 2002;39(suppl 1):S1-S266.
10 Eschbach JW, Egrie JC, Downing MR, Browne JK, Adamson JW: Correction of the anemia of end-stage renal disease with recombinant human erythropoietin: Results of a combined phase I and II clinical trial. N Engl J Med 1987; 316:73-78.

11 Evans RW, Rader B, Manninen DL, the Cooperative Multicenter EPO Clinical Trial Group: The quality of life of hemodialysis recipients treated with recombinant human erythropoietin. JAMA 1990;263:825-830.

12 Revicki DA, Brown RE, Feeny DH, Henry D, Teehan BP, Rudnick MR, Benz RL: Healthrelated quality of life associated with recombinant human erythropoietin therapy for predialysis chronic renal disease patients. Am J Kidney Dis 1995;25:548-554.

13 Obrador GT, Ruthazer R, Arora P, Kausz AT, Pereira BJG: Prevalence of and factors associated with suboptimal care before initiation of dialysis in the United States. J Am Soc Nephrol 1999;10:1793-1800.
14 Allon M, Kleinman K, Walczyk M, Kaupke C Maroni BJ, Heatherington A, Olson K, MesserMann L: The pharmacokinetics of novel erythropoiesis stimulating protein (NESP) following chronic intravenous administration is timeand dose-linear. J Am Soc Nephrol 2000;11: 248A, abstract.

15 Macdougall IC: An overview of the efficacy and safety of novel erythropoiesis stimulating protein (NESP). Nephrol Dial Transplant 2001;16(suppl 3):14-21.

16 Ibbotson T, Goa KL. Darbepoetin alfa. Drugs 2001;61:2097-2104.

17 Vanrenterghem Y, Jadoul M, Foret M, Walker $\mathrm{R}$, on behalf of the European/Australian 20000144 Study Team: Novel erythropoiesis stimulating protein (NESP) administered once every three weeks by the intravenous or subcutaneous route maintains hemoglobin (hb) in dialysis patients. American Society of $\mathrm{Ne}$ phrology/International Society of Nephrology Meeting, San Francisco, October 2002. 